\title{
School lunch and learning behaviour in primary schools: an intervention study
}

\author{
R. Golley ${ }^{1}$, E. Baines ${ }^{2}$, P. Bassett ${ }^{2}$, L. Wood ${ }^{1}$, J. Pearce $^{1}$ and M. Nelson ${ }^{1}$ \\ ${ }^{1}$ School Food Trust, Moorfoot, Sheffield S1 4PQ, UK and ${ }^{2}$ Psychology \& Human Development, Institute of Education, \\ 25 Woburn Square, London WC1H OAA, UK
}

Anecdotal evidence from teachers and parents describe dramatic improvements in children's concentration, behaviour and learning when healthier school food is introduced. However, a recent systematic review ${ }^{(1)}$ has concluded that no firm inferences can be drawn on the relationship between nutrition, including school food, and educational outcomes because of a lack of clear evidence. The aim of the present study was to determine whether (a) improvements in school food provision at lunchtime to meet the food-based standards ${ }^{(2)}$ and (b) changes to the school lunchtime dining room environment to meet best practice improved pupils' concentration and made them more alert and calm in the classroom in the learning period after lunch.

Six primary schools in Sheffield were recruited and matched in triplets by school and neighbourhood characteristics. The intervention was in two 6-week phases: in two of the matched schools, changes in food provision were followed by changes in the dining room environment; in two schools, changes in environment were followed by changes in food provision; two schools acted as controls. Observers made objective measurements of learning-related behaviours ${ }^{(3)}$ in the classroom during the teaching session immediately after lunch at three time points (baseline (pre-intervention); after 4-6 weeks; after 10-12 weeks (post intervention)) in 146 randomly-selected pupils aged $8-10$ years.

The three groups of schools (nutrition first, environment first and control) were similar in relation to size (average 435 pupils), English as an additional language (2\%) and special educational needs (30\%), but differed in relation to free school meal eligibility (7\% in control schools v. 24\%-27\% in the intervention schools). The ethnicity of the pupils taking part was very similar across all schools. Baseline assessment took place in January-May 2007. 'On-task' behaviours (measure of concentration) and 'off-task' behaviours (measure of disengagement (disruption)) were observed within three settings (pupil-teacher interaction, pupil-pupil interaction and working alone).

The study findings show that pupils in the intervention schools were 3.4 times more likely to be 'on-task' (OR $3.40, P=0.009)$ in the teacher-pupil setting compared with pupils in the control schools. Contrary to expectations, however, 'on-task' pupil-pupil behaviour was less likely in the intervention group compared with the control group. Similarly, 'off-task' pupil-pupil behaviour was more likely in the intervention group than in the control group.

The observations of pupil learning behaviours in the classroom after lunch suggest that the school food and dining room intervention resulted in an increase in levels of alertness (concentration and/or engagement) among pupils in the hour after lunch, but that the expression of this raised alertness is different in the individual, pupil-pupil, and teacher-pupil settings. The findings are consistent with the anecdotal evidence from teachers that pupils are more 'on-task' following a healthier lunch in school.

1. Centre for Food, Physical Activity and Obesity Research (2006) A systematic review of the effect of nutrition, diet and dietary change on learning, education and performance of children of relevance to UK schools. http://www.food.gov.uk/multimedia/pdfs/systemreview.pdf

2. UK Parliament (2008) The Education (Nutritional Standards and Requirements for School Food) (England) Regulations 2007 (SI 2007/2359) as amended by the Education (Nutritional Standards and Requirements for School Food) (England) (Amendment) Regulations 2008 (SI 2008/1800). London: The Stationery Office.

3. Blatchford P, Baines E, Rubie-Davies C et al. (2006) J Educ Psychol 98, 750-765. 